\title{
Microbial keratitis: A five years retrospective clinical study in tertiary eye hospital of eastern region of Nepal
}

\section{Puri LR', Shrestha GS ${ }^{2}$}

'Lila Raj Puri, Medical Director, Sagarmatha Chaudhary Eye Hospital, Lahan; ${ }^{2}$ Gauri Shankar Shrestha, Program co-ordinator, B.P. Koirala Lions Centre for Ophthalmic Studies, Institute of Medicine, Maharajgunj, Kathmandu.

\begin{abstract}
Background: Corneal ulcer is a sight threatening disease of significant public health concern. Early diagnosis with microbiological identification of the causative organism and institution of the proper medical therapy are important for successful visual recovery.

Objectives: To find out the demographic and predisposing factors associated with corneal ulcers, evaluate management of ulcers on the basis of clinical features and corneal scraping results.

Methods: It was a retrospective clinical study conducted among 1897 subjects with microbial keratitis in Sagarmatha Choudhary Eye Hospital, Lahan, Nepal from January 2010 to December 2014. Assessment included detailed eye examination with slit lamp for size, depth and location of ulcer, presenting visual acuity on internally illuminated Snellen's chart, and corneal scrapings for Gram's stain and 10\% Potassium hydroxide wet mount. A standard treatment was delivered on the basis of clinical features and corneal scraping results. Subjects were evaluated subsequently after 48 hours, one week, two weeks, three weeks and four weeks of initiation of therapy. Non-responding cases were admitted to perform re-scraping and to modify therapy.

Results: Majority of subjects (71.2\%) belonged to the age group of 26 to 55 years (71.2\%), presented after two weeks (82.3\%) and used non-prescription eye drops (71.9\%) before visiting to the eye hospital. Ocular trauma (54.5\%) was the most commonly reported predisposing factor. The central and paracentral ulcers comprised of $72.8 \%$ of ulcers withsize greater than $2 \mathrm{~mm}$ in $2.7 \%$ and moderate ulcer in $71.1 \%$. Microbiological test revealed fungal ulcers in $78.1 \%$ subjects. Presenting visual acuity better than $6 / 18$ was reported in $7 \%$ only.

Conclusion: Corneal ulcer was one of the commonly reported eye disease in Terai region of Nepal. Trauma is the commonest cause of corneal infection. Fungal corneal ulcers werecommonly noted.
\end{abstract}

Key words: Corneal scraping, Corneal ulcer, Microbial Keratitis

\section{INTRODUCTION}

Corno orneal infection is a major public health problem worldwide and the most common cause of monocular corneal blindness ${ }^{1,2}$. The incidence of ulcerative keratitis varies from 11 in 100000 per year in developed countries to 799 in 100000per year in developing countries ${ }^{3,4} \cdot$ Infective keratitis is a major public health problem in developing countries like Bangladesh, Sri Lanka and South India ${ }^{5-8}$. Occurrence of corneal ulcer is significantly associated with lower socio economic status ${ }^{8}$.

\section{Address for correspondence}

\section{Dr. Lila Raj Puri}

Medical Director, Eastern Regional Eye Care Program

Sagarmatha Chaudhary Eye Hospital, Lahan

Email:drlila_raj@yahoo.com
Diagnosis at an early stage with identification of the causative organism as indicated by microbiological assay and immediate institution of the propermedical therapy are important for successful visual recovery ${ }^{9-11}$. Poor visual outcome of microbial keratitis is associated with various factors such as older age, delay in referral to a cornea specialist, topical steroid treatment, past ocular surgery, poor vision at presentation, large size of the ulcer and central location of the ulcer ${ }^{12}$.

Most patients belong to rural areas in Nepal and India. Investigations such as microbiological evaluation and culture sensitivity are necessary for proper management of the ulcer. The present study was carried out to find out the demographic and predisposing factors of corneal ulcers, evaluation and management of ulcers on the basis of clinical features and corneal scraping results. 


\section{METHODS}

\section{STUDY DESIGN AND SAMPLE SIZE}

A total of 9272 (1.53\%) cases of corneal ulcer were notedfollowing a review of 603,380 hospital medical records of Cornea Department of Sagarmatha Choudhary Eye Hospital (SCEH), Lahan, Nepal from January 2010 to December 2014. The cases were notedin 2215 (23.9\%) subjects in 2010, $1502(16.2 \%)$ subjects in 2011, 1607 (17.3\%) subjects in 2012, 1933 (20.8\%) subjects in 2013 and 2015 (21.7\%) subjects in 2014.Among them, only 1897 (20.4\%) subjects were included into the study (Figure 1). The subjects having corneal ulcer impeding to or with actual perforation at the time of presentation, corneal ulcer with subtotal or total corneal melting at the time of presentation, the cases having viral keratitis, the ulcer presented in healing stage, the unavailability of report of scraping of children, lost follow up examinations and unavailability of complete clinical data were excluded from the study. This study was conductedin accordance with the Declarationof Helsinki of 2004 and was approved bythe institutional ethical committee of SCEH, Lahan.

\section{EXAMINATION}

Demographic data related to age and gender was noted. History related to predisposing factors, previous treatment, and duration of symptoms was also noted. Presenting visual acuity was recorded by an internally illuminated Snellen's chart at six meter distance. All the subjects were examined using slit lamp biomicroscopyto record size, depth and location of ulcer along with examination of margins, floor and infiltrations. Presence or absence of hypopyon was also recorded. Examination of ocular adenexa including lids, eyelashes, conjunctiva and lacrimal sac area was performed. Patency for the lacrimal system was assessed by performing syringing.

Loss of corneal epithelium with underlying stromal infiltrate and suppuration associated with signs of inflammation, with or without hypopyon is considered as corneal ulceration ${ }^{13,14}$. Corneal ulcers are classified as presented in Table 1.

\section{INVESTIGATION}

Corneal surface scraping was performed gently in every subject after explaining the procedure to them and having received an informed verbal consent from them. The base and leading edges were scraped from periphery to center. The material was smeared on two slides, one for $10 \%$ Potassium hydroxide $(\mathrm{KOH})$ wet mount preparation and another forGram's stain.

\section{TREATMENT}

The therapy was started on the basis of clinical examination and laboratory staining results. After detailed investigations, ciprofloxacin $\mathrm{HCL} 0.3 \%$ eye drop was prescribed initially. Combination of fortified cefazoline $5 \%$ and gentamicin $1.4 \%$ was given in nonresponding casesby 10-14 days. Oral Ciprofloxacin (500mg twice daily for seven days) was added to the subjects for an ulcer near the limbus. Natamycin 5\% eye drop was prescribed initially for the treatment of the fungal corneal ulcers covering less than $50 \%$ of corneal thickness. Oral ketoconazole tablets $3.3-6.6 \mathrm{mg} / \mathrm{kg}$ body weight daily were added for deeper corneal infection ( $>50 \%$ of corneal thickness) after liver function test. Voriconazole eye drop an hourly was added into the therapy in non-responding cases.

A combination therapy of antibacterial and antifungal drugs was delivered tothe ulcers having a mixed infection identified on either clinical examination or corneal scrapings, and in the ulcers having contradicting findings between clinical features and the report of scraping.

In severe and moderate ulcers, antimicrobials were prescribed in every five minutes during the first hour, then in every 15 minutes for next two hours. For uncooperative subjects antimicrobials were prescribed in every 15 minutes for three to four hours. After that, both of the groups received antimicrobials every hour for next two days. In mild ulcers, antimicrobials were prescribed two hourlyfor two days. These subjects were reexamined after 48 hours and response to the therapy was evaluated on the basis of signs of inflammation and symptomatic relief.

Atropine sulfate $1 \%$ eye drop three-time daily was delivered to all subjects as supportive therapy. Systemic carbonic anhydrase inhibitor (Acetazolamide) $1.5 \mathrm{mg} /$ $\mathrm{kg}$ body weight was delivered to the subjects for ulcer extending to the limbusand subjects having secondary glaucoma.

Subjects showing improved outcome on symptoms and inflammation were reevaluated in seven days and two to three weeks. Subjects showing nonimprovement or progression of the ulcer were admitted to assess compliance, perform re-scraping followed by modificationof therapy according to lab findings and the response to treatment after 48 hours of initiating therapy. Responding cases were discharged after seven days. Repeated epithelial debridement was performed 
in recalcitrant fungal ulcers to increase drug penetration. Subjects presenting with corneal ulcer perforation or impending perforation were treated either by cyanoacrylate glue application or tarsorrhaphy or conjunctival grafting. Outcome of treatment was recorded at each follow up examination. Status of healing (Table 1) was evaluated and noted on each follow up as outcome of the treatment at each follow up examination. Change in visual acuity was also recorded at each follow up examination.

Subjects were kept on follow up till complete resolution of ulcer was observed. Antimicrobials were prescribed four times a day after complete healing for one week in bacterial and for two weeks in fungal corneal ulcer to prevent recurrences.

\section{RESULTS}

During the five years study period, 1897 subjects $(20.5 \%)$ having corneal ulcer were enrolled into the study comprising of 1020 males (53.8\%) and 877 (46.2\%) females. Including a case of bilateral corneal ulcer, altogether 1898 eyes got affected with corneal ulcer. More than half of the subjects (51.6\%) belonged to the age group 26-45 years (Table 2). Seasonal variation of corneal ulcer was not significantly different though more number of subjects were examined during June to August (27.4\%). More than half of the subjects (58.5\%) presented to the hospital after three weeks of onset of symptoms of corneal ulcer. Majority of subjects (61.9\%) used non-prescription medications purchased from either local people or drug stores before registration to the hospital. These included antibiotics in 382 (20.1\%) subjects, antifungals in 161 (8.5\%) subjects, steroids in $315(16.6 \%)$ and more than one medication in $316(16.7 \%)$ subjects. Trauma was the most common predisposing factor in 1034 (54.5\%) subjects following unknown cause in 846 subjects (44.6\%).

Characteristics of corneal ulcer are presented in table 3 . The majority of ulcers (72.8\%) werecentral and para- central whereas 87 ulcers (4.8\%) involved peripheral part of cornea. Most of the ulcers (53.4\%) involved mild depth of corneal involvement ( $<20 \%$ of the corneal thickness) followed by moderate depth of corneal involvement (20$50 \%$ of the corneal thickness) in $46.1 \%$. Majority of the ulcers $(71.1 \%)$ were moderate in size $(2-5 \mathrm{~mm})$ followed by large size in $21.6 \%$ ulcers. On corneal scraping, 734 $(38.7 \%)$ ulcers were isolated as fungal ulcers, 748 (39.4\%) ulcers were mixed fungal and bacterial ulcers, 188 (9.9\%) ulcers were bacterial ulcers. No organism was identified in 228 (12.0\%) ulcers.

According to the World Health Organization (WHO) criteria of blindness, unilateral blindness (visual acuity $\leq 3 / 60$ ) was noted in $1367(76.1 \%$ ) eyes, $6 / 24$ to $4 / 60$ in 397 (20.9\%) eyes and normal (visual acuity $\geq 6 / 18$ ) in 133 (7.0\%) eyes at the time of presentation.

After one week, 611 (33.2\%) subjects showed recovery with minimal scars and prescribed a maintenance therapy for an extra one week. Similarly, 1286 (66.8\%) subjects needed second re-examination. Out of 1286 ulcers, 1113(86.5\%) ulcers were in healing stage, 42 $(4.4 \%)$ ulcers were in the stage of deterioration even leading to perforation in 14 eyes (25\%). Visual acuity was improved in 560 (43.5\%) eyes, decreased in 101 (7.8\%) eyes and stable in 625 (48.6\%) eyes on second follow up.

Out of 1286 subjects who visited SCEH for second follow up, $762(59.3 \%)$ subjects needed third re-examination at SCEH. On follow up, among 762 ulcers, 653 (85.7\%) ulcers were healing and 68 (8.9\%) were deteriorating clinically, even leading to perforation of 24 eyes (35.3\%). On third follow-up, visual acuity improved in 495 (64.9\%) eyes and deteriorated in 93 (12.2\%) eyes.

Finally, 448 (23.6\%) subjects needed fourth reexamination and found complete resolution of ulcers leaving corneal scars only. Thirteen eyes needed evisceration later on because of severe progression of ulcer in which anatomical integrity was not possible to save. 
Table 1: Classification of corneal ulcers

\begin{tabular}{|c|c|c|}
\hline \multicolumn{2}{|l|}{ Classification } & Criteria \\
\hline \multirow{3}{*}{ Grading } & Mild & $\begin{array}{l}\text { Size }<2 \mathrm{~mm} \text {; Depth }<20 \% \text { of corneal depth with superficial infiltration; Sclera involvement- } \\
\text { absent }\end{array}$ \\
\hline & Moderate & $\begin{array}{l}\text { Size } 2-5 \mathrm{~mm} \text {; Depth } 20-50 \% \text { of corneal depth with infiltration up to mid-stroma; Scleral } \\
\text { involvement- present or absent }\end{array}$ \\
\hline & Severe & $\begin{array}{l}\text { Size }>5 \mathrm{~mm} \text {; Depth }>50 \% \text { of corneal depth with stromal infiltration; Scleral involvement- } \\
\text { present or absent } \\
\text { All ulcers with involvement of central } 3 \mathrm{~mm} \text { of cornea }\end{array}$ \\
\hline \multirow{3}{*}{ Location } & Central & Ulceration in central 3mm of cornea \\
\hline & Paracentral & Ulceration in 3-6 mm of cornea from center \\
\hline & Peripheral & Ulceration beyond central $6 \mathrm{~mm}$ from center. \\
\hline \multirow{4}{*}{$\begin{array}{l}\text { Status of } \\
\text { healing }\end{array}$} & Healing & $\begin{array}{l}\text { Subject feels symptomatically better; epithelial defect, stromal infiltration, endothelial plaque } \\
\text { and anterior chamber reaction decreased or were absent. }\end{array}$ \\
\hline & No change & Epithelial defect and stromal infiltration were as same as presentation. \\
\hline & Progressed & Epithelial defect, stromal infiltration and corneal thinning increased \\
\hline & deteriorated & anatomical integrity couldn't be maintained Corneal perforation, need evisceration \\
\hline
\end{tabular}

\section{Table 2: Distribution of subjects with corneal ulcers}

\begin{tabular}{|c|c|c|c|}
\hline \multicolumn{2}{|l|}{ Categories } & Number & Percentage \\
\hline \multirow{7}{*}{ Age (Years) } & $\leq 15$ & 47 & 2.5 \\
\hline & $16-25$ & 223 & 11.7 \\
\hline & $26-35$ & 489 & 25.8 \\
\hline & $36-45$ & 490 & 25.8 \\
\hline & $46-55$ & 371 & 19.6 \\
\hline & $56-65$ & 212 & 11.2 \\
\hline & $>65$ & 65 & 3.4 \\
\hline \multirow{2}{*}{ Gender } & Males & 1020 & 53.8 \\
\hline & Females & 877 & 46.2 \\
\hline \multirow{4}{*}{ Seasonal variation } & December to February & 469 & 24.7 \\
\hline & March to May & 419 & 22.1 \\
\hline & June to August & 520 & 27.4 \\
\hline & September to November & 489 & 25.8 \\
\hline \multirow{2}{*}{ Geographical location } & East Terai of Nepal & 1602 & 84.4 \\
\hline & North-East part of India & 295 & 15.6 \\
\hline \multirow{4}{*}{ Time of Presentation } & First week & 333 & 17.5 \\
\hline & Second weeks & 451 & 23.8 \\
\hline & Third week & 601 & 31.6 \\
\hline & Fourth week & 512 & 26.9 \\
\hline \multirow{5}{*}{ Medication before hospital registration } & None & 723 & 38.1 \\
\hline & Antibiotics & 382 & 20.1 \\
\hline & Antifungals & 161 & 8.5 \\
\hline & Steroids & 315 & 16.6 \\
\hline & Two or more & 316 & 16.7 \\
\hline \multirow{4}{*}{ Predisposing factor } & Ocular trauma & 1034 & 54.5 \\
\hline & Dacryocystitis & 13 & 0.7 \\
\hline & Lagophthalmos & 4 & 0.2 \\
\hline & Unknown & 846 & 44.6 \\
\hline Total & & 1897 & 100 \\
\hline
\end{tabular}




\section{Table 3: Characteristics of corneal ulcers}

\begin{tabular}{|c|c|c|c|}
\hline Categories & & Number & Percentage \\
\hline \multirow{6}{*}{ Location of the ulcer } & Central & 344 & 18.1 \\
\hline & Paracentral & 180 & 9.5 \\
\hline & Peripheral & 87 & 4.6 \\
\hline & Central +Paracentral & 858 & 45.2 \\
\hline & $\begin{array}{l}\text { Central + Paracentral + } \\
\text { Peripheral }\end{array}$ & 322 & 17.0 \\
\hline & Paracentral +Peripheral & 107 & 5.6 \\
\hline \multirow{3}{*}{ Depth of the ulcer } & $<20 \%$ of the corneal thickness & 1013 & 53.4 \\
\hline & $\begin{array}{l}20-50 \% \text { of the corneal } \\
\text { thickness }\end{array}$ & 876 & 46.1 \\
\hline & $>50 \%$ of the corneal thickness & 9 & 0.5 \\
\hline \multirow{3}{*}{ Size of the ulcer } & $>5 \mathrm{~mm}$ & 410 & 21.6 \\
\hline & $2-5 \mathrm{~mm}$ & 1349 & 71.1 \\
\hline & $<2 \mathrm{~mm}$ & 139 & 7.3 \\
\hline \multirow{3}{*}{ Severity of ulcer } & Mild & 139 & 7.3 \\
\hline & Moderate & 1349 & 71.1 \\
\hline & Severe & 410 & 21.6 \\
\hline \multirow{4}{*}{ Microbiological isolation } & Bacteria & 188 & 9.9 \\
\hline & Fungal & 734 & 38.7 \\
\hline & Mixed & 748 & 39.4 \\
\hline & Unidentified & 228 & 12.0 \\
\hline Total & & 1898 & 100 \\
\hline
\end{tabular}

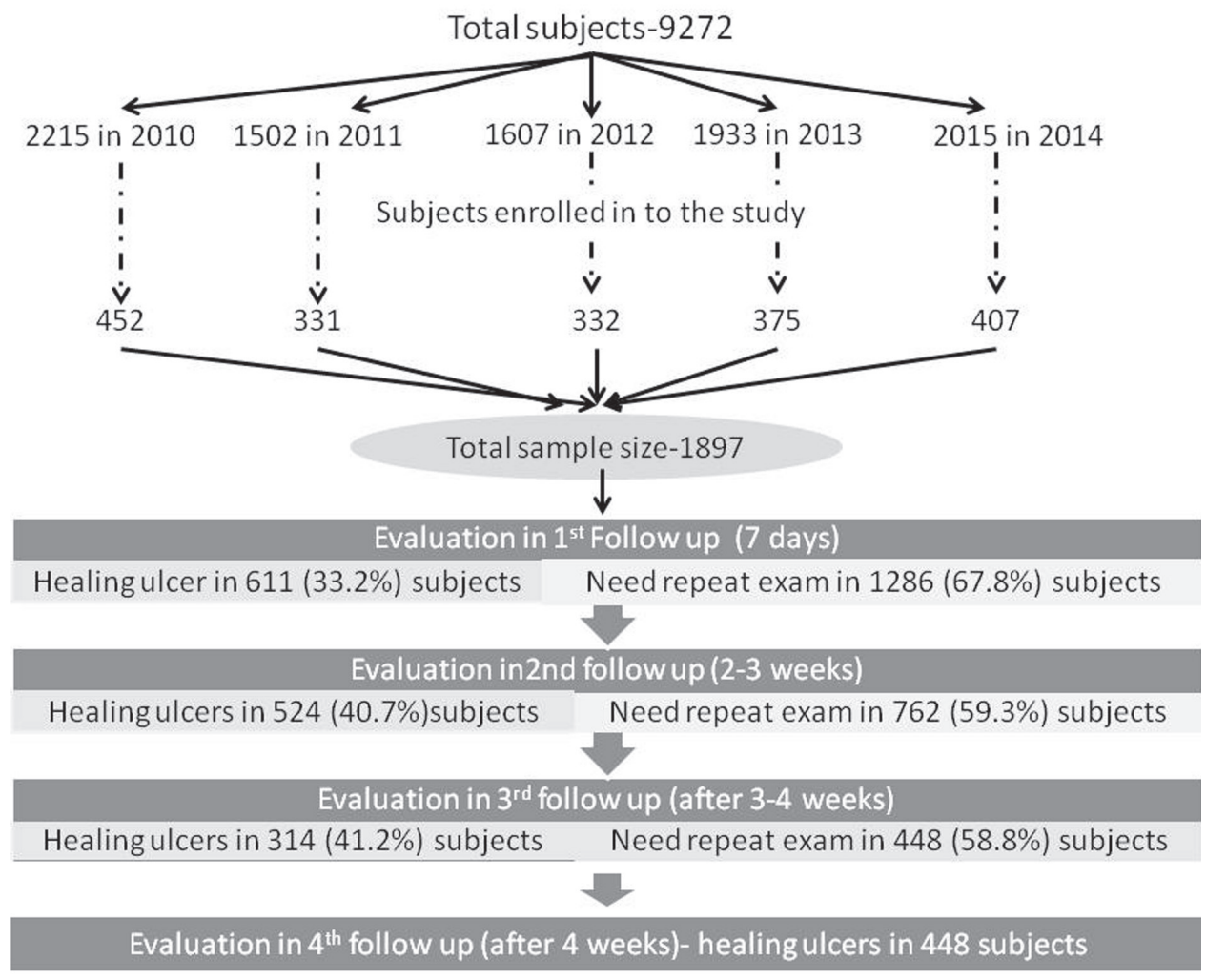

Figure 1: Flowchart showing the pattern of participants in the study. 


\section{DISCUSSION}

The present study was conducted to find out demographic and predisposing factors among subjects with corneal ulcers, its evaluation and management on the basis of clinical features and finding of corneal scraping along with compliance to the treatment.

Majority of the subjects (71.2\%) belonged to the age group of 26 to 55 years. The age group is socioeconomically very active and morbidity would affect entire families. The most predisposing factor for the ulcer was ocular trauma in 1034 subjects (54.5\%) which included people mostly engaged in agriculture.Ocular trauma explains the predisposing factor of corneal ulcers as in agricultural and developing countries like Nepal ${ }^{4}$. However seasonal preponderance for ocular trauma was not observed (Table 2). In this part of the world, paddy is harvested and maize is grown during the months December to May. Therefore, increased incidence of ocular trauma should have been reported. But this is the not the case in our study.

In a large number of subjects having corneal ulcer, the predisposing factors were unknown (44.8\%) where as ocular conditions accounts for corneal ulcers in less than one percentage. Schaefer et $\mathrm{al}^{9}$ reported ocular diseases as a major predisposing factors and Bourcier et $\mathrm{al}^{15}$ reported contact lenses as a major risk factor.The spectrum of corneal ulcer presentation worldwide has large variations due to difference in geographical and socio economic structures. Looking at these findings, our study demands a systematic improvement in clinical evaluation and management in hospital patients.

Ocular trauma was found relatively higher among males than females in the literatures ${ }^{13,16}$. Our finding also suggests a similar trend. This finding may explain the reason that, males are mostly involved in outdoor activities than females and seek medical services more than females do.

Most of the ulcers were moderate $(71.1 \%)$ to severe $(21.6 \%)$ grade and presentation (>one week in $82.5 \%$ ) was also late in the studyas in Upadhyay et al study, where $43.7 \%$ subjects and in Gonxales et al study, where $60.8 \%$ subjects were presented to eye examinationafter one week of onset of symptoms ${ }^{17,18}$. Late presentation could be related to possibility of poor public awareness towards receiving eye health facility services and distance to receiving the services. Most of them received initial treatment from local people including paramedical and medical personnel other than ophthalmologists, relatives, traditional healer and even directly from drug stores that accounts for $61.9 \%$. Local purchase of steroid eye drop was noted in 315 (16.6\%) subjects. Topical steroids can suppress inflammation and lessen the symptoms that may also cause late presentation to the eye hospital.

Pure fungal infection was noted in 734 (38.7\%) subjects and fungal infection associated with bacterial infection in 748 (39.4\%) subjects. The field work trauma mostly with the vegetative matter predisposes to fungal infection ${ }^{4,13}$. Association of fungal keratitis with use of corticosteroid and diabetes mellitus has been well documented in literatures ${ }^{18-22}$. The incidence of fungal infection was very high in our study than in other studies in this part of world. Other studies reported fungal infections between 8 to $40 \%{ }^{13,23,24}$. One reason could be due to our study population largely belonging to agricultural background and rural community. Another reason could be related to using topical corticosteroids (16.6\%) before visiting to the hospital.

Though isolated bacterial infection was low (9.9\%), coinfection caused by fungus and bacteria was very high (39.4\%). Recent series from India reported bacteria in $5 \%$ to $25 \%$ of keratomycosis $s^{11,13,25,27}$. Other laboratories in Asia and South America have isolated bacteria in approximately $30 \%$ to $60 \%$ of corneal specimen during fungal keratities ${ }^{4,28,29}$. This diverse prevalence may indicate non-conformity in distinguishing microbial coinfection, differences in risk factors, variation in climate and access to care. The sensitivity and specificity of bacterial detection in Gram's stain is inferior to that of culture method for detecting fungal filaments by $10 \%$ $\mathrm{KOH}$ preparation ${ }^{30,31}$. The sensitivity of $10 \% \mathrm{KOH}$ test in detecting fungal filaments is $90-99 \% \%^{23,32}$. Sensitivity of Gram stain in detection of bacteria is $36.0 \%$ in early and $40.9 \%$ in advanced keratitis;specificity is $84.9 \%$ and $87.1 \%$ respectively ${ }^{14}$. This can also be a reason for less bacterial detection in our series.

Microbiological work-up is now recommended in all suspected cases of microbial keratitis. In the McDonell et al (1992) study, only $10 \%$ ophthalmologist were having the facility of the Gram stain and only 14.5\% of all ulcers were examined withthe scraping for Gram stain and culture $^{33}$. Commonly practitioners start empirical treatment with antimicrobials for ulcers and microbiological evaluation is carried out only in nonresponding cases $^{33}$. This practice is applicable if bacterial infection is the dominating cause of ulcers. If fungal infection is predominating cause of corneal ulcers, this 
approach is not recommended. Jones suggests initial and applicable therapeutic treatment on the basis of corneal smear, clinical features and severity of keratitis for fungal corneal infections $s^{34}$.

In our study, Natamycin eye drops and systemic ketoconazole were prescribed in deeper penetrated fungal corneal ulcers ${ }^{35}$. While bacterial ulcers were treated with either ciprofloxacine eye drops or combination fortified cefazolin and gentamicin eye drops $^{36-38}$.

We notedthat 38 ulcersdevelopedperforations, 13 eyes needing evisceration. Various reasons may be responsible for having such kind of complication. For example, poor subjects compliance, resistant cases, prolonged use of topical steroids and microorganisms others than fungus and bacteria.

Follow up rate was not encouraging as only two third patients came for follow-up. Those subjects with constant follow up encouragingly showed corneal healing in $85 \%$

\section{REFERENCES}

1. Brilliant LB, Pokhrel RP, Grasset NC, Lepkowski JM, Kolstad A, Hawks W, et al. Epidemiology of blindness in Nepal. Bull World Health Organ. 1985;63:375-86.

2. Chirambo MC, Tielsch JM, West KP, Katz J, Tizazu T, Schwab $L$, et al. Blindness and visual impairment in southern Malwai. Bull World Health Organ. 1986;64:567-72.

3. Erie JC, Nevitt MP, Hodge DO, Ballard DJ. Incidence of ulcerative keratitis in a defined population from 1950 through 1988. Arch ophthalmol. 1993;111:1665-71.

4. Upadhyay MP, Karmacharya PC, KoiralaS,Shah D, Shakya S, Shrestha J, et al. The Bhaktapur eye study: ocular trauma and antibiotic prophylaxis for the prevention of corneal ulceration in Nepal. $\mathrm{Br} \mathrm{J}$ Ophthalmol. 2001; 85: 388-92.

5. Katz NNK, Wadud SA, Ayazuddin M. Corneal ulcer diseases in Bangladesh. Annals of Ophthalmology. 1983;15:834-6.

6. Bharathi MJ, Ramakrishnan R, Vasu S, Meenakshi R, Shivkumar C, Palaniappan R. Epidemiology of bacterial keratitis in a referral centre in south India. Indian J Med Microbiol. 2003;21:239-45.

7. Gonawardana SA, Ranasinghe KP, Arseculeretnae $\mathrm{SN}$, Seimor CR, Ajello L. Survey of mycotic and bacterial keratitis in Sri Lanka. Mycopathologia. 1994;127:77-81. and improvement in visual acuity in only $43.5 \%$. Corneal ulcers were mostly central and paracentral in $80.3 \%$, greater than $2 \mathrm{~mm}$ in $88 \%$, greater than $20 \%$ in depth in $44.3 \%$ and moderate to severe in $92.7 \%$. At last, only $24.3 \%$ had actually completed the therapy.

Major limitation of this study is not having included complicated cases of corneal ulcers presented to our hospital in this study. Large number of children was excluded owing to lack of general anesthesia. These exclusions may affect the present finding and may show a slight different outcome. So, generalizability to the population may not be possible.

\section{CONCLUSION}

In conclusion, corneal ulcer is a major eye problem. If treatment is started at an early stage, basic laboratory investigations coupled with clinical features is very helpful in effective management of corneal ulcers. Topical fluoroquinolones and natamycin supported with fortified cefazoline, gentamycin and voriconazole are effective in uncomplicated cases.

8. Vajpayee RB, Ray M, Panda A, Sharma N, Taylor HR, Murthy GV, et al. Risk factors for paediatric presumed microbial keratitis: a case control study. Cornea. 1999;18:565-9.

9. Schaefer F, Bruffin O, Zografos L, Guex-Crosier Y. Bacterial keratitis: a prospective clinical and microbiological study. $\mathrm{Br} J$ Ophthalmol. 2001;85:842-7.

10. Maske R, Hill JC, Oliver SP. Management of bacterial corneal ulcers. Br J Ophthalmol. 1986;70:199-201.

11. Satpathy G, Vishalakshi P. Ulcerative keratitis: microbial profile and sensitivity pattern-a five year study. Ann Ophthalmology. 1995;27:301-6.

12. Meidziak Al, Miller MR, Rapuano CJ, Laibson PR, Cohen EJ. Risk factors in microbial keratitis leading to penetrating keratoplasty. Ophthalmology. 1999; 106:1166-71.

13. Srinivasan $M$, Christine AG, George C, Cevallos V, Mascarenhas JM, Asokan B, et al. Epidemiology andaetiological diagnosis of corneal ulceration in Madurai. Br J Ophthalmol. 1997;81:965-71.

14. Sharma $S$, Kunimoto DY, Gopinathan U, Athmanathan S, Garg P, Rao GN. Evaluation of corneal scraping smear examination methods in diagnosis of bacterial and fungal keratitis: a survey of eight year of laboratory experience. Cornea. 2002;21:643-7. 
15. Boucier T, Thomas F, Borderie V, Chaumeil C, Laroche L. Bacterial Keratitis:Predisposing factors, clinical and microbiological review of 300 cases. $\mathrm{Br}$ J Ophthalmol. 2003;87:430-6.

16. Gonxales CA, Srinivasan M, Whitcher JP, Smolin G. Incidence of corneal ulceration in Madurai. Ophalmicepidemiol. 1996;3:159-66.

17. Upadhyay MP, Karmacharya PC, Koirala S, Tuladhar NR, Bryan LE, Smolin G, et al. Epidemiological characteristics, predisposing factors, ulceration in Nepal. Am J Ophthalmol. 1991;111:92-9.

18. Wilhelmus KR. Indecision about corticosteroids for bacterial keratitis; an evidence-based update. Ophthalmology. 2002;109:835-42.

19. Gopinathan U, Garg $P$, Fernandes $M$, Sharma S, Athmanathan S, Rao GN. The epidemiological features and laboratory results of fungal keratitis: a ten year review in a referral eye care centre in south India. Cornea. 2002;21:555-9.

20. Agrawal PK, Roy P, Das A, Banerjee A, Maity PK, Banerjee AR. Efficacy of systemic and topical Itraconazole as a broad spectrum antifungal agent in mycotic corneal ulcer: A preliminary study. Indian J Ophthalmol. 2001;49: 173-6.

21. Foster RK, Rabel IG. The diagnosis and management of keratomycosis. Arch ophthamol. 1975;93: 975-8.

22. Mohanty PK, Ambekar VA. Prevalence of mycotic infection of external eye. Indian J Ophthalmol. 1984;32: 153-5.

23. Bharathi MJ, Ramakrishnan R, Vasu S, Meenakshi $R$, Palaniappan R. Epidemiological characteristics and laboratory diagnosis of fungal keratitis: A three year study. Indian J Ophthalmol. 2003 Dec;51(4):315-21.

24. Chander J, Sharma A. Prevalence of fungal corneal ulcer in northern India. Infection. 1994;22:207-9.

25. Leck AK, Thomas PA, Hagan M, Kaliamurthy J, Ackuaku E, John M, et al. Etiology of suppurative corneal ulcer in Ghana and South India and epidemiology of fungal keratitis. Br J Ophthalmol. 2002;86:1211-5.

26. Basak S, Mohanty A, Mohanta A, Bhowmick A. Epidemiological and microbiological diagnosis of suppurative keratitis in Gangetic West Bengal, eastern India. Indian J Ophthalmol. 2005; 53: 17-22.

27. Choudhary A, Singh K. Spectrum of fungal keratitis in northern India.Cornea. 2005; 24: 8-15.

28. Laspina $F$, Samudio $M$, Cibils $D, T a ~ C N$, Fariña $\mathrm{N}$, Sanabria R, et al. Epidemiological characteristic of microbiological results on patients with infectious corneal ulcer: a 13 years survey in Paraguay. Grafes Arch Clin Exp Ophthalmol. 2004;242:204-9.

29. Khanal B, Deb M, Panda A, Sethi SS. Laboratory diagnosis in ulcerative keratitis. Ophthalmic Res. 2005; 37: 123-7.

30. Asbell $P$ and Stenson S. Ulcerative keratitis survey of 30 years: Laboratory experience. Arch Ophthalmol. 1982;100: 77.

31. Wahi JC, Katz HR, Abrams DA. Infectious keratitis in Baltimore. Ann Ophthalmol. 1991;23:234-7.

32. Vajpayee RB, Angra SK, Sandramouli S, Honavar SG, Chhabra VK. Laboratory diagnosis of keratomycosis: Comparative evaluation of direct microscopy and culture results. Ann Ophthalmol. 1993;25:68-71.

33. McDonell PJ, Nobel J, Gauderman WJ, Lee P, Aiello A, Trousdale M. Community care of corneal ulcers. Am J Ophthalmol. 1992;114:531-8.

34. Jones DB. Decision-making in the management of microbial keratitis. Ophthalmology. 1981;88:814-20.

35. O’Day DM. Selection of appropriate antifungal therapy. Cornea. 1987; 6: 238-45.

36. O`Brien, Maguire MG, Fink NE, Alfonso E, McDonnell P. Efficacy of Ofloxacin versus Cefazoline and tobramycin in the therapy of bacterial keratitis: report from the bacterial keratitis study group. Arch Ophthalmol. 1995;113:1257-65.

37. Prajna NV, George C, et al. Bacteriological and clinical efficacy, Ofloxacin $0.3 \%$ versus Ciprofloxacin $0.3 \%$ ophthalmic solution in treatment of patients with culture positive bacterial keratitis. Cornea. 2001; 20: 175-8.

38. Morlet N, Daniell M. Microbial keratitis: What is the preferred initial therapy? View-2: Empirical fluoroquinolone therapy is sufficient initial treatment.Br J Ophthalmol. 2003; 87: 1169-72. 